\title{
$\mathrm{ZnO}$ 나노 막대 성장을 위한 기판층으로서 hexagonal $\beta$ 상 $\mathrm{Ni}(\mathrm{OH})_{2}$ 나노 시트 합성 및 미세구조 분석
}

황성환 · 이태일 · 최지혁 · 명재민 ${ }^{\dagger}$

연세대학교 신소재공학과 정보전자재료연구실

\section{Synthesis of Hexagonal $\beta-\mathrm{Ni}(\mathrm{OH})_{2}$ Nanosheet as a Template for the Growth of $\mathrm{ZnO}$ Nanorod and Microstructural Analysis}

\author{
Sung-Hwan Hwang, Tae Il Lee, Ji-Hyuk Choi and Jae-Min Myoung ${ }^{\dagger}$ \\ Information and Electronic Materials Research Laboratory, Department of Materials Science and Engineering, \\ Yonsei University, 134 Shinchon-Dong, Seoul 120-749, Korea
}

(2010년 12월 23일 접수 : 2011년 1월 7일 최종수정 : 2011년 1월 7일 채택)

\begin{abstract}
As a growth-template of $\mathrm{ZnO}$ nanorods $(\mathrm{NR})$, a hexagonal $\beta-\mathrm{Ni}(\mathrm{OH})_{2}$ nanosheet $(\mathrm{NS})$ was synthesized with the low temperature hydrothermal process and its microstructure was investigated using a high resolution scanning electron microscope and transmission electron microscope. Zinc nitrate hexahydrate was hydrolyzed by hexamethylenetetramine with the same mole ratio and various temperatures, growth times and total concentrations. The optimum hydrothermal processing condition for the best crystallinity of hexagonal $\beta-\mathrm{Ni}(\mathrm{OH})_{2} \mathrm{NS}$ was determined to be with $3.5 \mathrm{mM}$ at $95^{\circ} \mathrm{C}$ for $2 \mathrm{~h}$. The prepared $\mathrm{Ni}(\mathrm{OH})_{2} \mathrm{NSs}$ were two dimensionally arrayed on a substrate using an air-water interface tapping method, and the quality of the array was evaluated using an X-ray diffractometer. Because of the similarity of the lattice parameter of the (0001) plane between $\mathrm{ZnO}$ (wurzite $\mathrm{a}=0.325 \mathrm{~nm}, \mathrm{c}=0.521 \mathrm{~nm}$ ) and hexagonal $\beta-\mathrm{Ni}(\mathrm{OH})_{2}$ (brucite $\mathrm{a}=0.313 \mathrm{~nm}, \mathrm{c}=0.461 \mathrm{~nm}$ ) on the synthesized hexagonal $\beta-\mathrm{Ni}(\mathrm{OH})_{2} \mathrm{NS}, \mathrm{ZnO}$ NRs were successfully grown without seeds. At $35 \mathrm{mM}$ of divalent $\mathrm{Zn}$ ion, the entire hexagonal $\beta-\mathrm{Ni}(\mathrm{OH})_{2} \mathrm{NSs}$ were covered with $\mathrm{ZnO} \mathrm{NRs}$, and this result implies the possibility that ZnO NR can be grown epitaxially on hexagonal $\beta-\mathrm{Ni}(\mathrm{OH})_{2} \mathrm{NS}$ by a soluble process. After the thermal annealing process, $\beta-\mathrm{Ni}(\mathrm{OH})_{2}$ changed into $\mathrm{NiO}$, which has the property of a p-type semiconductor, and then $\mathrm{ZnO}$ and $\mathrm{NiO}$ formed a $\mathrm{p}-\mathrm{n}$ junction for a large area light emitting diode.
\end{abstract}

Key words $\underline{\beta-\mathrm{Ni}(\mathrm{OH})_{2}}$, template, nano sheet, hydrothermal process, $\mathrm{ZnO}$.

1. 서

최근 수열 합성법으로 성장시킨 단결정 $\mathrm{ZnO}$ 나노 막대 는 n-type 발광 소자 재료로서 주목을 받고 있다. 현재까 지 단결정 p-type $\mathrm{GaN}$ 를 기판층으로하여 수열 합성법으로 $\mathrm{ZnO}$ 나노 막대를 성장시키거나 p-type $\mathrm{NiO}$ 를 스퍼터링 방 법으로 증착하고 $\mathrm{ZnO}$ 씨드를 그 위에 형성한 뒤 $\mathrm{ZnO}$ 나 노 막대를 합성하여 발광 소자를 구현한 연구가 있어 왔 다. ${ }^{1-4)}$ 그러나 진공 공정 및 고가의 단결정 기판을 사용하 지 않고 저 공정 비용으로 대면적 발광 소자를 개발하기 위해 $\mathrm{ZnO}$ 나노 막대와 epitaxial 성장이 가능한 습식 공 정 기반의 p-type 반도체 재료의 발굴 및 합성법에 대한 연구가 요구된다. 결정학적으로 wurzite 구조를 가지는 $\mathrm{ZnO}$ 의 c-axis 방향으로의 epitaxial 성장을 위해서는 기판층으

${ }^{\dagger}$ Corresponding author

E-Mail : jmmyoung@yonsei.ac.kr (J. -M. Myoung)
로서 brucite 구조의 (0001) 면이 가장 적합하다. Brucite 구조의 대표적 물질로는 $\beta-\mathrm{Mg}(\mathrm{OH})_{2}, \beta-\mathrm{Co}(\mathrm{OH})_{2}$ 그리고 $\beta-\mathrm{Ni}(\mathrm{OH})_{2}$ 가 있는데 이 중 가장 화학적으로 안정하고 전 기 광학적 특성이 우수한 p-type 반도체로 전환 될 수 있 는 재료는 $\beta \mathrm{Ni}(\mathrm{OH})_{2}$ 로 알려져 있다.

$\mathrm{Ni}(\mathrm{OH})_{2}$ 는 $\mathrm{Ni}$ 를 사용하는 알칼라인 충전용 배터리 $(\mathrm{Ni} /$ $\mathrm{Cd}, \mathrm{Ni} / \mathrm{H}_{2}, \mathrm{Ni} / \mathrm{Fe}, \mathrm{Ni} / \mathrm{Zn}$ )에 사용되는 물질로 구조적으로 는 육방 조밀 충전의 층상 구조를 가진 두 가지 상(phase) $\alpha$ 와 $\beta$ 으로 존재한다. ${ }^{5-11)}$ 결정학적 구조는 두 개의 육방 조밀 충전된 수산기 면 사이에 하나의 $\mathrm{Ni}$ 원자 면으로 이 루어져 있다. 이 적층 방향은 (0001)이며 반데르발스 힘 에 의하여 약하게 결합되어있다. $\beta \mathrm{Ni}(\mathrm{OH})_{2}$ 는 격자상수 $\mathrm{a}=0.313 \mathrm{~nm}, \mathrm{c}=0.461 \mathrm{~nm}$ 인 육방 조밀 충전 단위 격자를 가지며, 이를 $400^{\circ} \mathrm{C}$ 에서 열처리하여 면심 입방 정계를 가 지는 p-type 반도체인 $\mathrm{NiO}$ 를 얻을 수 있다. ${ }^{2)}$ 일반적으로 $\beta-\mathrm{Ni}(\mathrm{OH})_{2}$ 의 제조는 $25 \%$ 암모니아수에 $\mathrm{Ni}\left(\mathrm{NO}_{3}\right)_{2}$ 를 가수 분해 시키고 $200^{\circ} \mathrm{C}$ 수열 합성법을 통해 단결정 $\beta-\mathrm{Ni}(\mathrm{OH})_{2}$ 
를 얻는다. $\beta-\mathrm{Ni}(\mathrm{OH})_{2}$ 와 결정학적-제조 공정적 유사성을 가 지면서 n-type 반도체인 $\mathrm{ZnO}$ 는 격자상수 $\mathrm{a}=0.325 \mathrm{~nm}$, $\mathrm{c}=0.521 \mathrm{~nm}$ 인 육방 조밀 충전 단위 격자를 가지며 수열 합성법을 통해 단결정 결정 나노 막대구조를 쉽게 얻을 수 있다. 만일 $\beta \mathrm{Ni}(\mathrm{OH})_{2}$ 위에 단결정 $\mathrm{ZnO}$ 나노 막대를 성장 시킨다면 나노 물질 기반 $\mathrm{pn}$ 접합 발광 다이오드로 의 응용이 가능할 것으로 생각된다.

본 논문에서는 위에서 살펴본 $\beta \mathrm{Ni}(\mathrm{OH})_{2}$ 와 $\mathrm{ZnO}$ 의 (0001) 면상 결정학적 유사성에서 착안하여 먼저 $\mathrm{p}$-type 반도체 소재인 $\mathrm{NiO}$ 의 전구체로서 $\beta \mathrm{Ni}(\mathrm{OH})_{2}$ 단결정을 합성하고 그 결정학적 구조를 분석하였으며 $\beta \mathrm{Ni}(\mathrm{OH})_{2}$ 의 $\mathrm{ZnO}$ 나 노 막대를 epitaxial 성장 시키기 위한 단결정 기판층으 로서 가능성을 실험적으로 검증하였다.

\section{2. 실험 방법}

물에 분산된 $\beta-\mathrm{Ni}(\mathrm{OH})_{2}$ 나노 시트를 얻기 위하여 2 가 $\mathrm{Ni}$ 이온을 hexamethylenetetramine (HMTA)를 사용하여 가수분해와 축합 반응을 유도하였다. 2 가 $\mathrm{Ni}$ 이온의 소 스로는 $\mathrm{Ni}\left(\mathrm{NO}_{3}\right)_{2} \cdot 6 \mathrm{H}_{2} \mathrm{O}$ 를 사용하였고 전체 반응은 탈이온 수에서 이루어졌다. 최적의 합성 조건을 찾기 위하여 온 도, 농도, 반응 시간을 변수로 실험을 진행하였다. 합성 한 $\beta \mathrm{Ni}(\mathrm{OH})_{2}$ 나노 시트를 정제하기 위하여 $2,350 \mathrm{G}$ 로
10 분간 원심분리를 3 회 수행하였고 최종적으로는 이소프 로필 알코올에 분산하였다. 결정성 및 미세구조 분석을 위 하여 $\mathrm{X}$ 선 회절 분석기 $(\mathrm{XRD})$, 고분해능 주사전자현미경 (HRSEM)과 고분해능 투과전자현미경 (HRTEM)을 사용 하였다. $\mathrm{ZnO}$ 나노 막대의 $\beta \mathrm{Ni}(\mathrm{OH})_{2}$ 나노 시트 기판층 위로의 성장을 확인하기 위하여 과도핑 된 $\mathrm{p}^{++}$실리콘 기 판 위에 $\beta \mathrm{Ni}(\mathrm{OH})_{2}$ 나노 시트를 drop casing 하고 $60^{\circ} \mathrm{C}$ 1 시간 건조한 샘플 위에 2 가 $\mathrm{Zn}$ 이온 1.7 과 $35 \mathrm{mM}$ 의 농 도 조건에서 $\mathrm{HMTA}$ 를 사용하여 가수분해와 축합을 시켜 나노 막대를 성장하였다. 2가 $\mathrm{Zn}$ 이온의 소스로는 $\mathrm{Zn}\left(\mathrm{NO}_{3}\right)_{2}$ $\cdot 6 \mathrm{H}_{2} \mathrm{O}$ 를 사용하였고 전체 반응은 $80^{\circ} \mathrm{C}$ 탈이온수에서 이 루어졌다. 최종적으로 성장한 $\beta-\mathrm{Ni}(\mathrm{OH})_{2}$ 나노 시트 위에 $\mathrm{ZnO}$ 나노 막대는 $\mathrm{HRSEM}$ 을 통하여 그 표면 형상과 구 조적인 외관을 관찰하였다.

\section{3. 결과 및 고찰}

가장 좋은 결정성을 가지는 $\beta \mathrm{Ni}(\mathrm{OH})_{2}$ 나노 시트를 얻 기 위한 공정 온도, 시간, 농도별 합성 결과의 SEM 사 진들은 Fig. 1에 나타내었다. Ni 이온의 농도가 높아지면 $\beta-\mathrm{Ni}(\mathrm{OH})_{2}$ 로부터 $\alpha-\mathrm{Ni}(\mathrm{OH})_{2}$ 로 천이됨을 관찰 할 수 있 었다. 이는 농도가 과도하게 많은 경우 반응 속도가 지 나치게 증가하여 $\mathrm{Ni}(\mathrm{OH})_{2}$ 가 충분히 결정성을 갖추기까

\section{Temperature}

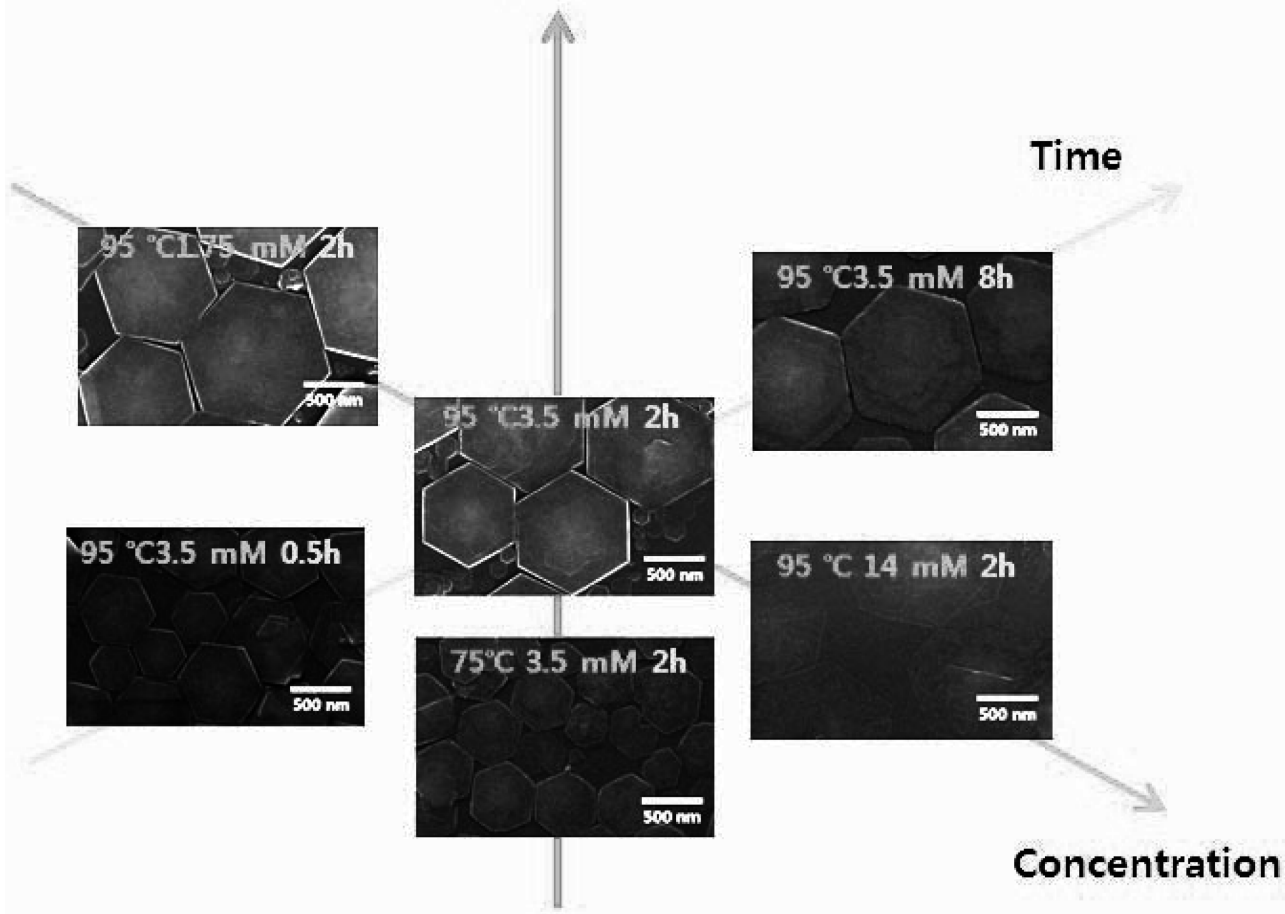

Fig. 1. SEM images of hexagonal $\beta-\mathrm{Ni}(\mathrm{OH})_{2}$ nanosheet for various temperature, concentration and time conditions. The best crystallinity was achieved under the $3.5 \mathrm{mM}$ at $95^{\circ} \mathrm{C}$ for $2 \mathrm{~h}$. 
지 시간이 주어지지 않기 때문인 것으로 생각된다. $\beta$ $\mathrm{Ni}(\mathrm{OH})_{2}$ 은 온도가 증가할수록 결정이 커지고 두꺼워지는 것을 관찰 할 수 있었다. 물을 기반으로 하는 합성 과정 이므로 물의 끓는점 이하로 온도가 제한되므로 본 논문 에서는 $95^{\circ} \mathrm{C}$ 까지 실험을 진행하였다. 이는 반응의 활성화 에너지를 충분히 줄 수 있는 고온의 경우가 저온의 경우 보다 결정성을 확보하는데 유리하기 때문이라고 생각된 다. 또한 반응 시간이 2시간이 지나게 되면 결정성이 감 소하게 되는데 이는 2 가 $\mathrm{Ni}$ 이온 소스의 고갈 이후에 열 화 반응이 일어나는 것으로 생각된다. 8시간 합성한 샘플 의 경우 표면이 녹아 내린 것을 관찰 할 수 있다. 결론 적으로 가장 좋은 결정성을 가지는 $\beta-\mathrm{Ni}(\mathrm{OH})_{2}$ 을 합성하 기 위한 최적 공정 조건이 $3.5 \mathrm{mM}, 95^{\circ} \mathrm{C}, 2$ 시간임을 확 인하였다.

Fig. 2는 drop casting 법을 이용하여 합성된 $\beta-\mathrm{Ni}(\mathrm{OH})_{2}$ 를 유리 기판 위에 2차원 배열시킨 결과 SEM 사진을 Fig. 2(a)에 나타내었다. 이소프로필 알코올의 표면 에너 지는 매우 작기 때문에 유리 기판 위에 매우 빠른 속도 로 퍼지게 되고 $\beta-\mathrm{Ni}(\mathrm{OH})_{2}$ 나노 시트들도 이소프로필 알 코올의 흐름에 따라 균일하게 수평으로 배열을 하게 된 다. 실험적으로 $\beta-\mathrm{Ni}(\mathrm{OH})_{2}$ 나노 시트의 농도가 높게 되 면 서로 간에 뭉침에 의하여 균일한 수평 배열이 어려워 지고 지나치게 낮은 농도에서는 주어진 기판에 빈 공간 이 많이 생기게 된다. 이 경우 여러 차례 공정을 반복할 지라도 균일한 수평배열이 어려운데 이는 먼저 배열된 시 트들에 새롭게 공급된 시트들이 걸리게 되어 뭉치는 결 과를 관찰 할 수 있었다. 적절한 농도 조건에서 좋은 수 평 배열을 할 수 있었고 그 수평 배열의 정도를 평가하 기 위하여 유리 기판 위에 배열된 $\beta-\mathrm{Ni}(\mathrm{OH})_{2}$ 나노 시트 들의 XRD 분석을 하였고 그 결과는 Fig. 2(b)에 나타내 었다. 결과적으로 $19.2^{\circ}$ 에서 (0001) 면에 해당하는 peak만 이 관찰되었는데 이는 모든 $\beta-\mathrm{Ni}(\mathrm{OH})_{2}$ 나노 시트들이 한 방향으로 정렬되었음을 의미한다. $\beta-\mathrm{Ni}(\mathrm{OH})_{2}$ 나노 시트들

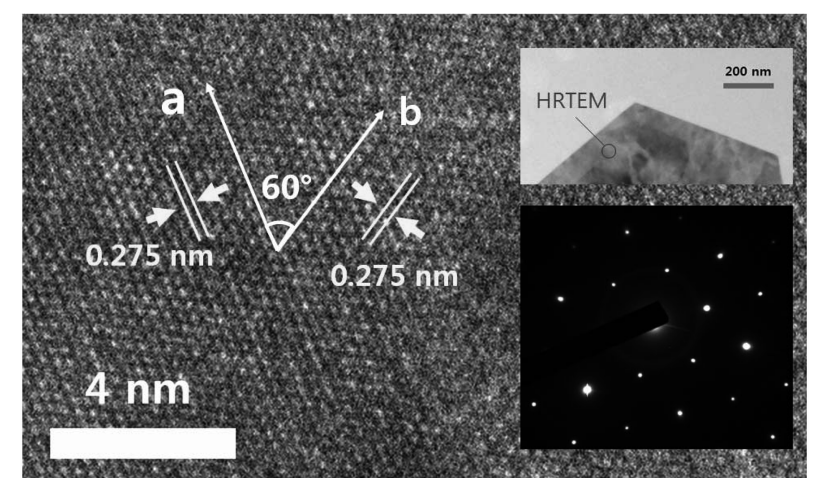

Fig. 3. HRTEM image of a hexagonal $\beta-\mathrm{Ni}(\mathrm{OH})_{2}$ nanosheet. The insets are its bright field image and SEAD pattern.

은 $\mathrm{ZnO}$ 나노 막대 성장을 위한 기판층 로서 역할을 하 기 위하여 위와 같이 한 방향 정렬을 해야만 소자응용에 적합한 구조를 가지게 된다.

Fig. 3은 합성한 $\beta \mathrm{Ni}(\mathrm{OH})_{2}$ 나노 시트의 결정학적 미세 구조를 분석한 결과이다. TEM 분석을 통해 정육각형의 반 복적인 selective area electron diffraction (SAED) pattern 들이 정확히 $60^{\circ}$ 의 각도를 가지고 배열되어 있음으로 $\beta$ $\mathrm{Ni}(\mathrm{OH})_{2}$ 나노 시트가 육방 조밀 충전 단위 격자를 가짐 을 확인 할 수 있었다. 또한 bright field image 로부터 $\beta$ $\mathrm{Ni}(\mathrm{OH})_{2}$ 나노 시트가 정육각형의 외관을 가짐을 관찰 할 수 있었다. HRTEM 으로부터 격자의 면간 거리가 $0.27 \mathrm{~nm}$ 로 측정되었고 면 방향간 정확히 $60^{\circ}$ 의 각도를 가짐을 관 찰 할 수 있었다. 이 면간 거리는 육방 조밀 충전 단위 셀의 격자 상수가 문헌에 보고된 것과 일치하는 $0.313 \mathrm{~nm}$ 값을 나타내었다. 그러므로 본 실험에서 합성한 $\beta-\mathrm{Ni}(\mathrm{OH})_{2}$ 나노 시트는 $\mathrm{ZnO}$ 나노 막대 성장을 위한 기판층 로서 적합한 것으로 평가되었다.

Fig. 4 는 $\beta-\mathrm{Ni}(\mathrm{OH})_{2}$ 나노 시트를 기판층으로 하여 $\mathrm{ZnO}$ 나노 막대를 5 시간 동안 성장 시킨 결과를 나타낸다. Fig. 4(a)에서 보는 바와 같이 저 농도 조건 $(1.7 \mathrm{mM})$ 에서는 $\mathrm{Zn}$ 이온의 공급이 주어진 기판층의 수에 비해 부족함으 (a)

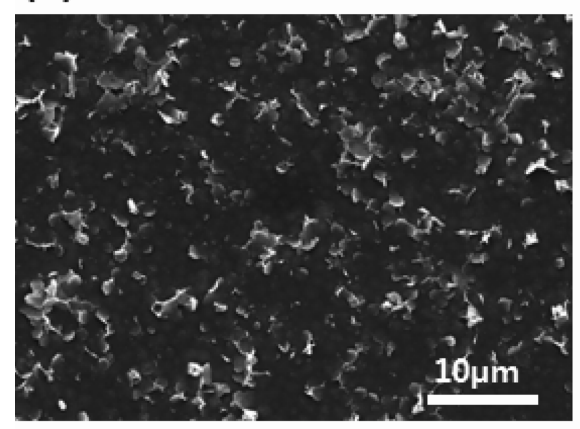

\section{(b)}

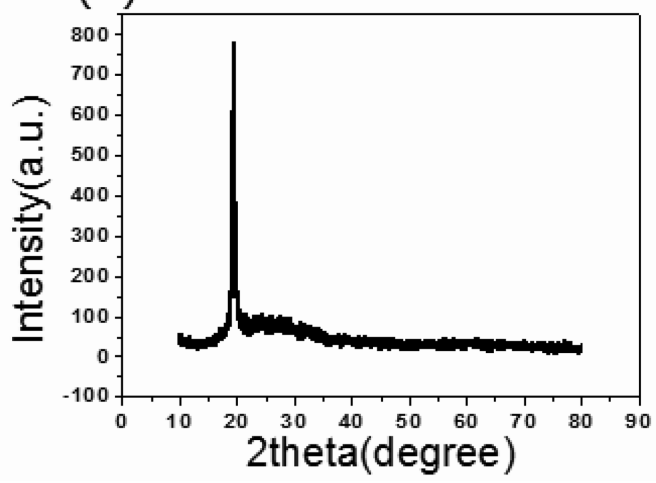

Fig. 2. (a) SEM image of two dimensionally arrayed hexagonal $\beta-\mathrm{Ni}(\mathrm{OH})_{2}$ nanosheet and (b) its XRD characteristics. 
(a)

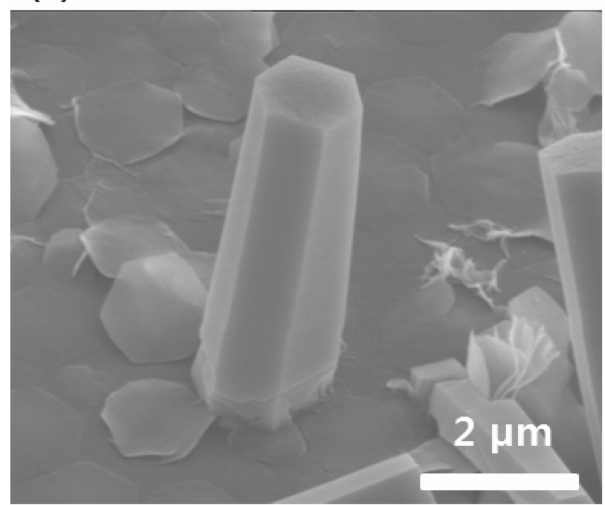

(b)

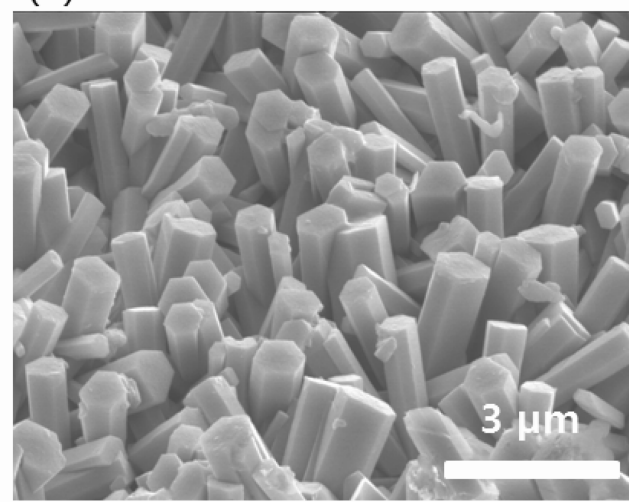

Fig. 4. On a template of hexagonal $\beta-\mathrm{Ni}(\mathrm{OH})_{2}$ nanosheet, $\mathrm{SEM}$ images of $\mathrm{ZnO}$ nanorods grown at (a) $1.7 \mathrm{mM}$ and (b) $35 \mathrm{mM}$ using a hydrothermal method.

로 간헐적으로 나노 막대가 성장 한 것을 관찰 할 수 있 었다. 반면에 고농도 $(35 \mathrm{mM})$ 에서는 $\mathrm{Zn}$ 이온의 공급이 원활하여 나노 막대가 $\beta \mathrm{Ni}(\mathrm{OH})_{2}$ 나노 시트 기판층 전체 에 걸쳐 성장 한 것을 Fig. 4(b)에서 관찰 할 수 있었다. 성장한 $\mathrm{ZnO}$ 나노 막대의 지름이 $\beta \mathrm{Ni}(\mathrm{OH})_{2}$ 나노 시트의 지름과 유사한 것으로 관찰 된 것으로 미루어 보아 $\mathrm{ZnO}$ 나노 막대가 기판층 기반으로 성장한 것을 확인 하였다. 또한 $\beta \mathrm{Ni}(\mathrm{OH})_{2}$ 나노 시트들의 (0001) 면이 기판에 수직 으로 놓여있지만 성장한 $\mathrm{ZnO}$ 나노 막대는 다양한 방향 을 가지고 자란 것을 관찰 할 수 있었는데 그 원인은 Fig. 1의 HRSEM 사진으로부터 $\beta-\mathrm{Ni}(\mathrm{OH})_{2}$ 나노 시트들 의 (0001) 표면에 kink, step, screw 전위 결함들이 존재하 기 때문으로 추정된다. $\mathrm{ZnO}$ 나노 막대가 성장 할 때에 이 러한 결함들에 의한 응력을 해소하기 위해 $\beta-\mathrm{Ni}(\mathrm{OH})_{2}$ 나 노 시트들의 (0001)면과는 다른 방향으로 성장된 것으로 생각된다.

\section{4. 결 론}

본 연구에서는 $\beta \mathrm{Ni}(\mathrm{OH})_{2}$ 와 $\mathrm{ZnO}$ 의 (0001)면상 결정학 적 유사성에서 착안하여 $\mathrm{ZnO}$ 나노 막대의 epitaxial 성장 을 위한 기판층으로서 $\beta-\mathrm{Ni}(\mathrm{OH})_{2}$ 나노 시트를 합성하고 그 미세구조를 분석하였고 실제적으로 $\mathrm{ZnO}$ 를 합성한 $\beta \mathrm{Ni}$ $(\mathrm{OH})_{2}$ 나노 시트 위에 성장 시켜 그 가능성을 평가하였 다. $\beta \mathrm{Ni}(\mathrm{OH})_{2}$ 시트의 최적 합성 조건은 가수분해 물질 로 HMTA 사용하여 $3.5 \mathrm{mM}, 95^{\circ} \mathrm{C}, 2$ 시간 임을 확인하 였다. 합성한 $\beta \mathrm{Ni}(\mathrm{OH})_{2}$ 시트의 (0001) 면상 면간 거리가 $0.27 \mathrm{~nm}$ 인 육방정계로서 $\mathrm{ZnO}$ 의 (0001)면상 결정학적 유사 성을 가짐을 확인하였다. $35 \mathrm{mM} \mathrm{Zn}$ 이온 농도에서 가수 분해 물질로 $\mathrm{HMTA}$ 사용하여 $\beta \mathrm{Ni}(\mathrm{OH})_{2}$ 시트를 기판층 으로 하여 $\mathrm{ZnO}$ 나노 막대를 성공적으로 성장 시켰다. $\mathrm{P}-$ type 반도체의 전구체인 $\beta-\mathrm{Ni}(\mathrm{OH})_{2}$ 위에 epitaxial 성장한
$\mathrm{ZnO}$ 나노 막대 구조는 $400^{\circ} \mathrm{C}$ 열처리 조건을 통해 $\beta$ $\mathrm{Ni}(\mathrm{OH})_{2}$ 를 축합시켜 $\mathrm{NiO}$ 로 전환한다면 $\mathrm{p}-\mathrm{n}$ 접합 다이오 드를 형성시킬 가능성을 가지고 있어 추후에 그 전기-광 학적 특성에 대한 연구를 진행할 예정이다.

\section{감사의 글}

본 연구는 $\mathrm{POSCO}$ Genesis 과제의 지원으로 수행 되 었습니다.

\section{참 고 문 헌}

1. H. Sun, Q. F. Zhang and J. L. Wu, Nanotechnology, 17, 2271 (2006).

2. Y. Y. Xi, Y. F. Hsu, A. B. Djurisic, A. M. C. Ng, W. K. Chan, H. L. Tam and K. W. Cheah, Appl. Phys. Lett., 92, 113505 (2008).

3. X. W. Sun, J. Z. Huang, J. X. Wang and Z. Xu, Nano Lett., 8, 1219 (2008).

4. S. K. Choi, S. H. Yi, J. M. Jang, J. A. Kim and W. G. Jung, Kor. J. Mater. Res., 17(5), 273 (2007) (in Korean).

5. F. S. Cai, G. Y. Zhang, J. Chen, X. L. Gou, H. K. Liu and S. -X. Dou, Angew. Chem. Int. Ed., 43, 4212 (2004).

6. X. J. Han, P. Xu, C. Q. Xu, L. Zhao, Z. B. Mo and T. Liu, Electrochim. Acta, 50, 2763 (2005).

7. X. Wang, H. Luo, P. V. Parkhutik, A. Millan and E. Matveeva, J. Power Sourc., 115, 153 (2003).

8. X. Liu and L. Yu, Mater. Lett., 58, 1327 (2004).

9. Q. S. Song, Y. Y. Li and S. L. I. Chan, J. Appl. Electrochem., 35, 157 (2005).

10. M. Cao, X. He, J. Chen and C. Hu, Cryst. Growth Des., 7, 170 (2007).

11. D. Yang, R. Wang, M. He, J. Zhang and Z. Liu, J. Phys. Chem. B, 109, 7654 (2005).

12. L. X. Yang, Y. J. Zhu, H. Tong, Z. H. Liang, L. Li and L. Zhang, J. Solid State Chem., 180, 2095 (2007). 